\title{
Roughness of the Asphalt Mix: Its Causes, Effects and Methods to Treat It
}

\author{
Surat Mahmoud Alqammaz
}

\begin{abstract}
This research aims at investigating roughness in asphalt mix, and to address its effects, causes and methods for treating it to provide safe and smooth driving for the drivers and to the roads users in order to reduce accidents, loss of properties and consumption of fuel which reflects on saving financial costs. The research has depended on qualitative research method through reviewing a number of previous studies related to road constructions, since the desired high quality of roads has become priority to the road users and to the environmentalists who seek to reduce air pollution and emission of harmful gases.

Keywords: Roughness of the cement mix, causes and effects, methods for treating defect and Roughness international rough-ness index.
\end{abstract}

\section{INTRODUCTION}

Expansion in the housing sectors, building new complexes, and the increasing number of people who own vehicles and using them for transportation, and for economic purposes in exports and import of different products and services which require the use of heavy trucks this rapid increase in the movement and use of the roads have led to the increase demand \& interest in quality of the roads regarding its pavement mix to attain the optimal usage, reduce fuel consumption, and safety at the roads, users. People use different means for transportation like cars, busses and trucks for different activities, whether commercial or industrial activities. Such an increasing activities require cement pavement mix which guarantee safe and cost-effective travel and usage of the roads. Roughness \& defects in the roads cause serious problems to the drivers and to the users of the roads. Asphalt concept pavement is the most common type of pavements around the world. Still, several factors can affect the quality and performance of the asphalt pavement surface. A good and in-depth understanding of these factors would enable pavement specialists to construct smooth, cost-effective, and long-lasting pavement to satisfy the needs expectations of the road users (Eibheiry, Kandil \& Kotop, 2011).

Manuscript received on November 30, 2021.

Revised Manuscript received on December 06, 2021.

Manuscript published on January 30, 2022.

* Correspondence Author

Surat Mahmoud Awwad Al-Qummaz*, Department of Civil Engineering, Mu'ta University, Jordan

(c) The Authors. Published by Blue Eyes Intelligence Engineering and Sciences Publication (BEIESP). This is an open access article under the CC BY-NC-ND license (http://creativecommons.org/licenses/by-nc-nd/4.0/)

\section{RESEARCH PROBLEM}

Research problem stems from the need for observing any possible roughness, defects and cracks, their sizes, length and serosity in establishing dangers to the roads users in order to guarantee smooth driving and safety to the users, since cracks treatment involves additional costs to the government, disturbing the daily movement for different reasons and prepossesses.

\section{RESEARCH QUESTIONS}

From the research problem emerge the following questions:

1. What are the causes of the defects and roughness in the asphalt paved roads?

2. What are the responsibilities of the road construction authority?

3. What are the effects of roughness of the asphalt paved roads?

4. What is the responsibility of ministry of public works and tender department in achieving quality assurance of the constructed roads?

\section{RESEARCH IMPORTANCES}

Research importance presents in dealing with an important issue which is roughness of the asphalt pavement of the roads for different usages, and its effect on the roads users, and on the social and environmental issues which might result in accidents and additional maintenance costs.

\section{RESEARCH OBJECTIVES}

Research objectives derive from research problems, these objectives include the follow:

1. To identify possible defects and roughness in the paved roads.

2. To identify and shed the light on causes of roughness and the associated problems.

3. To provide suggestions and recommendations in order to improve durability and quality of the roads.

4. To achieve maximum positive impact of the roads by minimizing roughness of the roads at all levels.

\section{LIMITATION OF THE RESEARCH}

- This research is limited asphalt pavement.

- It is limited to the topic, roughness the road pavement and its problems. 


\section{"Roughness of the Asphalt Mix: Its Causes, Effects and Methods to Treat it"}

- It is limited to its research methods qualitative research method and associated problems.

One of the main causes for reducing quality of the road pavement is roughness of the road's pavement surface.

Roughness of the road have direct influence on the environment, on traffic levels. Traffic jams, increases rate in the air. The pavement roughness is one of the most effective parameters that can be used as an indicator of the pavement performance. This parameter can also be used to evaluate the vehicle operating costs and safety regarding the pavement surface condition. Factors affecting pavement surface roughness include, traffic loading, pavement thickness, subgrade type and environmental factors (rain, snow, frost and storms and other environmental factors).

\section{PAVEMENT EVALUATIONS}

There are available four characteristics of pavement condition that can be used to evaluate the pavement quality:

- Pavement roughness.

- Service condition.

- Structural failure.

- Skid resistance (safety) (Elbheiry et al, 2011).

Pavement roughness can cause significant problem, including the increase of silicules, road structure damage, and decrease the ride quality (Giuseppe, C \& Giuseppe, L, 2010).

\section{DETERMINATION OF SURFACE ROUGHNESS OF VARIOUS PAVEMENTS}

The roughness of the road pavement constitutes the smoothness and frictional properties of the pavement surface and safety, and the case of driving path (Yero, Hainin, \& Yacoob, 2012).

\section{INTERNATIONAL ROUGHNESS INDEX}

The international roughness index is the standard scale for evaluating road roughness in many countries in the world. Since cities are apers with high density of living environments and active economic conditions. Due to human communication and economic activities arbane roads are usually planed are designed as interconnected networks, since they composed of roadways, side walks, drainage systems, transportation facilities, intersections, and auxiliary facilities (Chen, Lin, Tary, Chu \& Cheng, 2020). Its worth mentioning that rough surface of the road pavement wear more quickly and have higher friction coefficient than smooth surface. The roughness index depends on the road surface roughness, which depends on the finishing of the road surface, it is a function of the smoothness of the pavement and its comfort, safety, and convenience to the road users (Kusang, $\mathrm{H}$ et al, 1992).

\section{PAVEMENT ROUGHNESS AND FUEL CONSUMPTION}

Pavement roughness means how smooth the road is, which is considered as indicator at how comfortable the driving will be, also at the wear and tear of the vehicle, fuel efficiency, and the maintenance needs of the road (Green, Akbarian, Ulm \& Greyory, 2013).
Studies showed that all common pavement types deteriorate because of roughness pavement surface, depending on complexity of traffic volume, and pavement with more structural support have the lowest deterioration rate, with continuously reinforced asphalt aging performance.

\section{ROAD MAINTENANCE}

Road maintenance plays important role in reducing roughness of pavement surface, since understanding the impact of roughness coupled with the pavement deterioration rate and road design can help stakeholders understand ways to improve road design and maintenance schemes in order to minimize fuel use and consumption and greenhouse gas emission to maximize the use of limited road construction and maintenance funding (Greene, S et al, 2013).

\section{MEASURING ROUGHNESS}

Roughness can be measured through the appearance of potholes, ruts and cracks as major symptoms of a rough roads. Roughness also exists on a micro - scale in terms of the smoothness, or roughness of the pavement surface's texture. The driver's perception of roughness is subjective, it depends on the type of the vehicle, speed, and on individual's sensitivity. The American society for testing and materials defines pavement roughness as "the deviation of a surface from a true planar surface with characteristics dimensions that affect vehicle dynamics and ride quality's ASTM, 2012.

\section{A.The effect of roughness road pavement on fuel consumption.}

Roughness of road pavement surface is seen as increasing the amount of resistance a vehicle experience as it travels down the road, requiring additional amount of fuel to maintain a certain speed. Increased resistance translates to an increase in fuel consumption, since fuel efficiency is affected heavily and tied to the condition of the roads, and the interaction between pavement and the vehicle. Furthermore, the impact of pavement condition on vehicle fuel consumption has been investigated widely for different vehicles types under different operating, weather, and pavement conditions (Greene, S et al, 2013). Researchers have reached that roughness is an important measurement of road's health, it provides a standard platform for comparison of road networks, it helps giving the priority for road maintenance and reconstruction, often coupled with other factors like traffic volume.

\section{ROAD PAVEMENT STRUCTURE}

Road pavement structure is classified in to the sub-grade, sub-base, road base and the surfacing. Which consists of binding course and wearing course. The wearing course is the exposed topmost lager that provide the travel path. Skid resistance, safety and comfort to the road users. Road surface roughness depends on the finishing of the road surface, since a good road is expected to give an improved driving quality in terms of noise reduction, minimum delays at road works, enhances deformation resistance (Hunter, R, 2000).

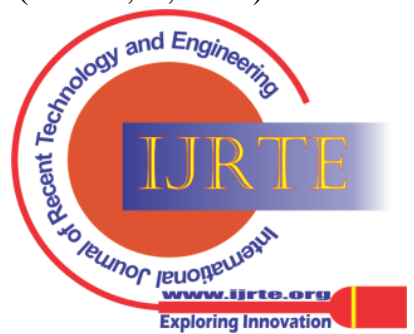




\section{CLASSIFICATION OF ROAD WAYS}

Roadways can be classified in to flexible pavement and rigid pavements according to their structural properties. In a flexible pavement, the wheel loads are transferred by grain-to-train contact of the aggregate through the gradual structure. This kind of pavement usually adopts a multi-layer design from bottom to top, there are subgrade, subbase, course, base course, and surface course, while in a rigid pavement, the wheel loads are transferred to the subgrade soil through the bending strength of the pavement. The flexible pavement has proper bending resistance and sufficient stability to support the traffic load (Papaginnakis, A, 2012).

\section{TREATMENT OF ASPHALT MIX ROUGHNESS}

Before the on-site inspection operation stars, the relevant information must be confirmed, and creating the inspection operation record sheet for the use of on0site inspection, using the inspection program system to observe the readings of the various sensors are normal. International roughness index data before road leveling covers a wide range of road smoothness (Chen, Sh et al, 2020).

\section{CONCLUSIONS}

Roughness of the asphalt mix pavement constitutes vary serious problems, because of its negative effects on smooth driving, safety of the roads users, additional expenses resulting from increase fuel consumption, and the negative environmental conditions resulting from emission of harmful gases such as $\mathrm{Co} 2$ gas. It is recommended to establish and use the appropriate paving schemes, using experienced equipment operators with sufficient experience to limit the roughness of the road pavement, leading to construct high quality and save roads especially with the increasing number of different types of vehicles wing the roads. Observation methods can be used the detect and treat roughness of the pavement surface. Roads construction authority needs to be aware of all forms of defects and roughness that may appear including any potential cracks, deformation, and roughness. Furthermore those who are responsible for roads construction need to select the most appropriate materials for the asphalt mix to be used for roads pavement to avoid roughness with it negative economic, social and financial effects. This can be archived through having available laboratories to test materials quality, and sizes according to the standards and requirement issued by ministry of public works, paying the due attention to detect causes of the appearance of roughness and its effect on quality of the roads and on the safe driving.

\section{REFERENCES}

1. Elbheiry, M., Kardil, Kh, Drd Kotob , A (2012). Investigating of factors affecting pavement roughness:" engineering Research Journal, 132. 1-13.

2. Giuseppe, C \& Giusepe, L (2010). Road roughness and whole body vibration, ASCE, 1-15.

3. Yero, S, Hainin, M \& Yucoob, H (2012). Determination of surface roughness index of various bituminous pavement IJRRAS, (1): 98-104.

4. Chen, SH, Lin, Ch, Tang, Ch, Chu, L \& Cherg, Ch, (2020). Research on the international roughness index Theshoid of road rehabilitation in metropolitan Areas: A case study in Tapiei city, sustainability, 12, 10536: 1-19.
5. Kwang, H, Morosiuk, G \& Emby, J (1992). Assessment of skid resistance and macrotexture of road surface in Malaysia, seventh REAA conference, Singapore: 443-449.

6. Greene, S, Akbarian, M, Ulm, F \& Gregory, J (2013). Pavement roughness and fuel consumption, CSHAB, Concrete sustainability $\mathrm{HaB}$.

7. Hunter, R (2000). Asphalt in road construction, 125-196.

8. Papagiannakis, A (2012). Pavement designe and materials, John Wiley \& sons, inc: Hoboken , $\mathrm{Nj}$, USA.

\section{AUTHORS PROFILE}

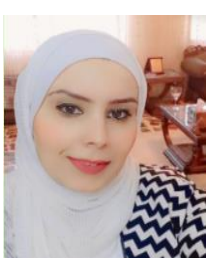

Surat Mahmoud Awwad Al-Qummaz., I live in Jordan in the city of Salt. I was born on November 30, 1988, in the capital, Amman. I graduated from Mu'ta University in 2011 with a specialization in civil engineering. I worked in several locations, including the New Salt Hospital from 2011 to 2012, where I was a site engineer and also worked in the Greater Salt Municipality from 2012 to this point as an engineer for service road projects. I got married in 2013 and have two sons, the first-named Muhammad, seven years old, and the second, Murad, four years old I love my job and my position at work. I aspire to promotion in my work and I aspire to complete my postgraduate studies in the field of road engineering Among my hobbies are reading and playing sports, including swimming, tennis, and yoga, and among the most important achievements that I have made as a result of reading, studies, and problems facing me in my work, I made a research paper that is the first from the beginning of my career, which are problems and defects of asphalt mixtures, and I aspire to publish more research on that.

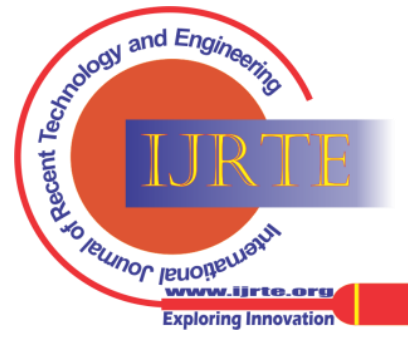

